\title{
Dickkopf-1: As a Diagnostic and Prognostic Serum Marker for Hepatocellular Carcinoma
}

\author{
Ahmed L Sharaf ${ }^{1}$, El-Said G El-Badrawy ${ }^{1}$, Naglaa A Khalifa ${ }^{2}$, \\ Sameh M Abdel Monem ${ }^{1}$, Hosam M Dawod ${ }^{1}$ \\ ${ }^{1}$ Tropical Medicine Department, Faculty of Medicine, Zagazig University, Egypt \\ ${ }^{2}$ Clinical Pathology Department, Faculty of Medicine, Zagazig University, Egypt
}

Corresponding Author Ahmed L Sharaf

Mobile:

$+201003584402$

E mail:

Drahmed_lotfy@hotm

ail.com

Key words:

Dickkopf-1, alpha-feto protein, hepatocellular carcinoma
Background and study aim: Hepatocellular carcinoma (HCC) accounts for $70-80 \%$ of all liver cancers and the 5-year survival is only $3-5 \%$. This bad prognosis is due to the lack of an effective method for early diagnosis. So, only $30-40 \%$ of patients with HCC are suitable for curative treatments at the time of diagnosis. Thus, there is a great need for tools to diagnose HCC early especially in cirrhotic patients. The aim of this work is to assess the validity of serum DKK1 as a diagnostic marker for $\mathrm{HCC}$ and to assess prognostic value of serum DKK1 in predicting treatment response, complication and survival in HCC patients.

Patients and Methods: This study included 60 Patients divided into two groups. Group A: consisted of 30 patients with post hepatitic $\mathrm{C}$ and/or $\mathrm{B}$ liver cirrhosis. Group B: consisted of 30 patients with $\mathrm{HCC}$ on top of post hepatitic C and/or B liver cirrhosis. Group B patients underwent either radiofrequency ablation or ethanol injection. Clinical assessment, routine laboratory evaluation, CT studies and measurement of serum alpha-fetoprotein (AFP) and DKK1 were performed to all patients and repeated to group $\mathrm{B}$ patients 1 and 3 months after treatment.

Results: The optimum cut off value of DKK1 for diagnosis of HCC was 4.3 $\mathrm{ng} / \mathrm{mL}$ (AUC 0.89, sensitivity $66.7 \%$ and specificity $96.6 \%) \quad(\mathrm{P}<0.001)$. While, the optimum cut off value for AFP was $>101$ $\mathrm{ng} / \mathrm{mL}$ with $90 \%$ sensitivity and $75.9 \%$ specificity $(p<0.001)$. Testing of both DKK1 and AFP increased the diagnostic accuracy for HCC (AUC 0.901, sensitivity 93.3\%, and specificity 75.9) $(\mathrm{P}<0.001)$. Serum DKK1 level significantly decreases after HCC treatment with either radiofrequency ablation or ethanol injection $(\mathrm{P}<0.001)$.

Conclusion: Testing of both DKK1 and AFP significantly increased the diagnostic accuracy for HCC. Meanwhile, DKK1 can be used alone for HCC diagnosis even in HCC with inconclusive AFP. DKK1 has a promising prognostic value and can be used for follow up of HCC patients who underwent loco-regional treatment.

hepatitis $\mathrm{C}$ infections, cirrhosis, chronic alcohol abuse, aflatoxin ingestion, nonalcoholic steatohepatitis and metabolic liver diseases [4]. Both $\mathrm{HCV}$ and HBV infections are the most common risk factors for $\mathrm{HCC}$ among Egyptian patients. $10 \%-20 \%$ of the general Egyptian populations are infected with HCV [5]. 80\% - 90\% of HCC patients have underlying cirrhosis and the remaining $10 \%$ - $20 \%$ of cases develop HCC without cirrhosis [6,7]. 
$\mathrm{HCC}$ is a disease with fast infiltrating growth and poor prognosis [8]. The commonly used screening methods for liver cancer are ultrasound examination of the liver and determination of serum AFP level [9]. Abdominal ultrasound is a better, simple and easy method for detection of $\mathrm{HCC}$ but it is operator dependent and many focal lesions can be missed [10]. AFP has approximately $60 \%$ specificity and $40 \%$ sensitivity for HCC diagnosis, since minor elevations are common in patients with chronic liver disease, cirrhosis, germ cell tumors and in pregnancy [11]. So, it is necessary to find a specific \& sensitive marker for early diagnosis of HCC and for monitoring of treatment response.

Dickkopf-1 (DKK1) is a secretory protein which was identified in 1998. DKK1 is an inhibitor of $\mathrm{Wnt} / \beta$-catenin signalling and a downstream target of $\beta$-catenin [12]. The $\mathrm{Wnt} / \beta$-catenin signalling pathway plays main role in development of both normal liver and hepatic carcinogenesis [13]. It is hardly expressed in normal human adult tissues except in placental and embryonic tissues [14]. DKK1 is up regulated in various cancers including breast, lung, ovarian, prostate cancers and $\mathrm{HCC}$ [15].

This work aimed to assess validity of serum DKK1 as a diagnostic marker for HCC and to assess prognostic value of serum DKK1 in predicting treatment response, complication and survival in HCC patients.

\section{PATIENTS AND METHODS}

This case control study was conducted in Tropical Medicine and Clinical Pathology Departments, Faculty of Medicine, Zagazig University Hospitals, Egypt during the period from January 2014 till March 2016.

This study included 60 Patients divided into two groups: Group A: consisted of 30 patients with post hepatitic $\mathrm{C}$ and/or B liver cirrhosis. Group B: consisted of 30 patients with HCC on top of post hepatitic $\mathrm{C}$ and/or $\mathrm{B}$ liver cirrhosis.

\section{Inclusion criteria}

Group (A) included cirrhotic patients with no evidence of hepatic focal masses in ultrasound evaluation. Cirrhotic patients are child class A or B according to Child Pugh score. Patients with liver cirrhosis were diagnosed by liver biopsy, laboratory and/or imaging evidence including (nodular liver contour, presence of ascites, portal hypertension, varices, enlargement of the caudate lobe, splenomegaly and collateral portal venous anastomoses).

Group (B) included patients with HCC on top of cirrhotic liver. HCC was diagnosed by CT criteria (filling of the dye in arterial phase and rapid fade out in venous and delayed phases) and/or by histopathology according to the American Association for the Study of Liver Diseases guidelines. HCC patients will be Child class A or B according to Child Pugh score for cirrhotic patients.

\section{Exclusion criteria}

Patients who had any other tumors or history of other tumors were excluded from the study. Also, patients with Child-Pugh class C, vascular invasion or extra hepatic metastasis were excluded from the study.

All patients were subjected to full history, complete physical examination and laboratory investigation in the form of liver function tests, kidney function tests, complete blood count, $\mathrm{AFP}$, viral markers (HBs $\mathrm{Ag}$ and $\mathrm{HCV}$ Abs) and serum DKK1. Also, all patients were subjected to abdominal ultrasound. HCC was diagnosed by triphasic CT examination of the abdomen or by liver biopsy (FNAB) (imaging is not conclusive). Group B patients underwent either radiofrequency ablation or ethanol injection according to the Barcelona Clinic Liver Cancer (BCLC) staging system and followed up by laboratory investigations (CBC, LFTs, KFTs, AFP, and DKK1), abdominal ultrasound and triphasic CT scan 1 and 3 months after treatment.

\section{Dickkopf-1 (DKK1)}

It was determined by Human Dickkopf-1(DKK1) ELISA Kits provided by WKEA MED SUPPLIES CORP, USA, according to the manufacturer's protocol. This kit allows for the determination of DKK1 concentrations in Human serum, plasma, and other biological fluids.

The kit assay Human DKK1 level in the sample, by using Purified Human DKK1 antibody to coat microtiter plate wells, make solid-phase antibody, then add DKK1 to wells, Combined DKK1 antibody which With enzyme labeled, become antibody - antigen - enzyme-antibody complex, after washing Completely, Add substrate, substrate becomes blue color At HRP enzyme-catalyzed, reaction is terminated by the addition of a sulphuric acid solution and the color change is 
measured spectrophotometrically at a wave length of $450 \mathrm{~nm}$.

The concentration of DKK1 in the samples is then determined by comparing the O.D. of the samples to the standard curve.

\section{Ethanol injection}

All lesions were injected by absolute alcohol; ultrasound guided in multiple sessions, once weekly, under complete aseptic condition and 10 mg midazolam as a sedative agent.

The same operator used spinal needle (20 gauges) to inject ethanol intra-lesionally and leave the needle for 2 minutes in place, then injection of local anesthetic during withdrawal of the needle to minimize the irritant effect of refluxed ethanol to the capsule.

The total amount of ethanol can be calculated according to the following equation:

$$
\mathrm{V}=4 / 3 \pi(\mathrm{r}+0.5)^{3}
$$

Where: V=Volume of ethanol, $\pi=22 / 7, r=$ radius of the tumor by $\mathrm{cm}$ plus $0.5 \mathrm{~cm}$ as safety margin. The average amount per session was 6.8 cc, with average 5 sessions per lesion and average amount of $35 \mathrm{cc}$ per lesion [16].

\section{Radiofrequency ablation}

All patients were fasted before the procedure. Treatment was performed with sedation using midazolam (Dormicum R $10 \mathrm{mg}$ amp; Roche) $0.03-0.1 \mathrm{mg} / \mathrm{kg} / \mathrm{IV}$ every 30 minutes, propofol (Diprivan R $20 \mathrm{mg}$ amp; Astra) $0.5 \mathrm{mg} / \mathrm{kg} / \mathrm{IV}$ over 3-5 minutes.

All lesions were ablated by the same operator hands, under complete aseptic condition at Ultrasonography Unit, Tropical medicine department. Multiple curved, retractable electrodes are kept inside the needle until its tip is positioned within a tumor. When properly positioned, a plunger on the hub of the needle is advanced so that the electrodes extend from the needle tip. Multiple electrode tips of an expanding electrode are active. This results in more homogenous heat distribution within the tumor and creates a reproducible sphere of ablation every time. Patients were observed for 6 hours for blood pressure, pulse, pain and vomiting.

\section{Statistical analysis}

All data were collected, tabulated and statistically analyzed using SPSS 20.0 for windows. Quantitative data were expressed as the mean \pm SD \& median (range), and qualitative data were expressed as an absolute frequencies "number"\& relative frequencies (percentage). Independent samples Student's t-test, Mann-Whitney U, Paired t-test and Wilcoxon signed ranks test were used when needed. Percent of categorical variables were compared using the Pearson's Chi-square test or Fisher's exact test when was appropriate. Receiver operating characteristic (ROC) curve analysis was used to identify optimal cut-off values of AFP and DKK1 with maximum sensitivity and specificity for diagnosis $\mathrm{HCC}$ and prediction of response, Area Under Curve (AUC) was also calculated. $\mathrm{P}<0.05$ was considered statistically significant (S).

\section{RESULTS}

This study showed no statistically significant difference between groups A \& B as regard age, sex, viral etiology and Child Pugh score. Most of our patients were males (42 patients) and HCV positive (51). Table (1) showed no statistically significant difference between group $\mathrm{A}$ and group B as regard laboratory data except for platelet count, DKK1 and AFP $(138.93 \pm 37.17$ Vs $110.76 \pm 38.61 \mathrm{P}=0.006),(2.28 \pm 0.90 \mathrm{ng} / \mathrm{ml}$ Vs $4.97 \pm 2.23 \mathrm{ng} / \mathrm{ml} \mathrm{P}<0.001)$ and $(70.38 \pm$ $80.52 \mathrm{ng} / \mathrm{ml}$ Vs $361.93 \pm 289.91 \quad \mathrm{P}<0.001)$, respectively. We found that serum DKK1 was more elevated in HCC patients with focal lesions $>3 \mathrm{~cm}$ than focal lesions $<3 \mathrm{~cm}(6.09 \pm 1.77 \mathrm{Vs}$ $2.75 \pm 1.09)(\mathrm{P}<0.001)($ Table 2$)$.

The optimum diagnostic cut off value for DKK1 was $>4.3 \mathrm{ng} / \mathrm{mL}$ with $66.7 \%$ sensitivity and $96.6 \%$ specificity while, the cut off value of AFP was $>101 \mathrm{ng} / \mathrm{mL}$ with $90 \%$ sensitivity and $75 \%$ specificity for HCC diagnosis vs. cirrhotic patients $(\mathrm{P}<0.001)$. Testing of both DKK1 and AFP increased the diagnostic accuracy for HCC compared with either test alone (AUC 0.901, 95\% CI $0.795-0.964$, sensitivity $93.3 \%$, and specificity 75.9) $(\mathrm{P}<0.001)$ (Table 3; Fig. 3).

Table (4) showed no statistically significant difference among studied group as regard bilirubin, albumin, PT, creatinine and CBC before and after treatment, whereas DKK1, AFP, ALT and AST showed statistically significant improvement in these patients after treatment. DKK1 levels before and after treatment were $4.97 \pm 2.23$ $\mathrm{ng} / \mathrm{ml}$ and $2.75 \pm 1.52 \mathrm{ng} / \mathrm{ml}$ respectively $(\mathrm{p}<0.001)$. This study showed highly statistically significant decline of DKK1 level among complete responder's patients $(\mathrm{P}<0.001)$ (Table 5). The cut off value of DKK1 (before treatment) for prediction of complete response to treatment was $\leq 5.67 \mathrm{ng} / \mathrm{mL}$ ( $<<0.001)$ (Table 6; Fig. 4). 
Table (1): Laboratory investigations and tumor markers of both groups

\begin{tabular}{|c|c|c|c|}
\hline Laboratory findings & Group A (N=30) & Group B (N=30) & P value \\
\hline AST (U/L) & $64.41 \pm 18.29$ & $70.46 \pm 31.65$ & $0.756(\mathrm{NS})$ \\
\hline ALT (U/L) & $64.06 \pm 18.54$ & $60.60 \pm 24.98$ & 0.391 (NS) \\
\hline Bilirubin (mg/dl) & $1.70 \pm 0.76$ & $1.93 \pm 0.77$ & $0.140(\mathrm{NS})$ \\
\hline Albumin (g/dl) & $3.29 \pm 0.49$ & $3.29 \pm 0.54$ & 0.769 (NS) \\
\hline PT (sec) & $15.27 \pm 1.62$ & $15.83 \pm 2.98$ & 0.249 (NS) \\
\hline Creatinine (mg/dl) & $0.93 \pm 0.18$ & $1.02 \pm 0.27$ & $0.154(\mathrm{NS})$ \\
\hline Hemoglobin (g/dl) & $11.46 \pm 0.60$ & $11.83 \pm 1.55$ & $0.306(\mathrm{NS})$ \\
\hline PIt $\left(\times 10^{3} / \mathrm{mm}^{3}\right)$ & $138.93 \pm 37.17$ & $110.76 \pm 38.61$ & $0.006(\mathrm{~S})$ \\
\hline WBCs $\left(\times 10^{3} / \mathrm{mm}^{3}\right)$ & $6 \pm 1.65$ & $5.81 \pm 2.17$ & 0.444 (NS) \\
\hline AFP (ng/dl) & $70.38 \pm 80.52$ & $361.93 \pm 289.91$ & $<0.001$ (HS) \\
\hline DKK 1 (ng/dl) & $2.28 \pm 0.90$ & $4.97 \pm 2.23$ & $<0.001(\mathrm{HS})$ \\
\hline
\end{tabular}

Table (2): Patients with focal lesion $<3 \mathrm{~cm}$ and patients with focal lesion $3-5 \mathrm{~cm}$ in group (B) as regard tumor markers

\begin{tabular}{|c|c|c|c|}
\hline & \multicolumn{3}{|c|}{ Group B $(\mathbf{N}=\mathbf{3 0})$} \\
\cline { 2 - 4 } & $<\mathbf{3 ~ c m}(\mathbf{N}=\mathbf{1 0})$ & $\mathbf{3}-\mathbf{5} \mathbf{~ c m}(\mathbf{N}=\mathbf{2 0})$ & P value \\
\hline AFP (ng/dl) & $422.30 \pm 349.55$ & $331.75 \pm 259.86$ & $0.468(\mathrm{NS})$ \\
\hline DKK 1 (ng/dl) & $2.75 \pm 1.09$ & $6.09 \pm 1.77$ & $<0.001(\mathbf{H S})$ \\
\hline
\end{tabular}

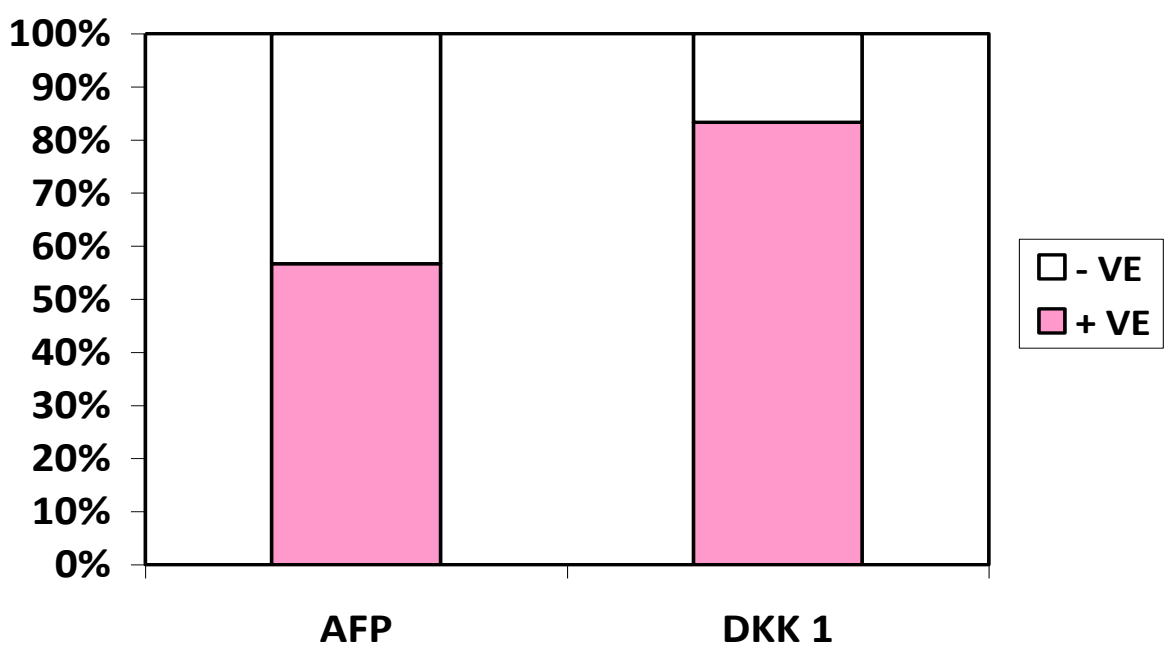

Fig. (1): Percentage of increased level of AFP and DKK 1 among $\mathrm{HCC}$ patients (group B) 


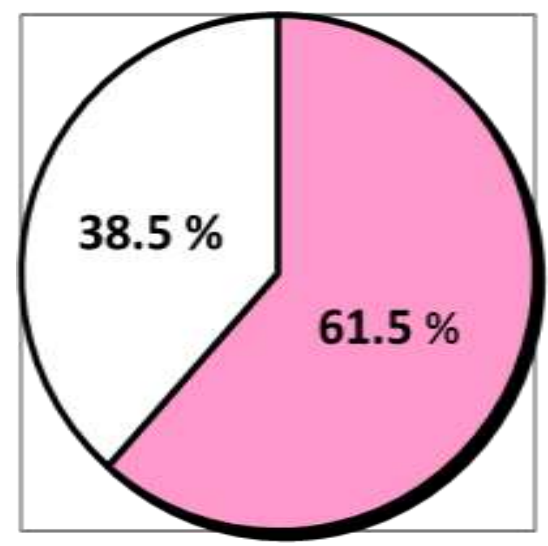

Fig. (2): Percentage of increased level of DKK1 among HCC patients with non-conclusive AFP

Table (3): Validity of DKK1, AFP and DKK1+AFP as diagnostic markers for HCC vs. cirrhotic patient without $\mathrm{HCC}$

\begin{tabular}{|c|c|c|c|c|c|}
\hline Cut-off value & $\begin{array}{c}\text { Sens. \% } \\
\text { (95\% CI) }\end{array}$ & $\begin{array}{c}\text { Spec. \% } \\
\text { (95\% CI) }\end{array}$ & $\begin{array}{c}\text { PPV \% } \\
\text { (95\% CI) }\end{array}$ & $\begin{array}{c}\text { NPV \% } \\
\text { (95\% CI) }\end{array}$ & $\begin{array}{c}\text { AUC } \\
(\mathbf{9 5 \%} \text { CI) }\end{array}$ \\
\hline DKK1 & $66.7 \%$ & $96.6 \%$ & $95.2 \%$ & $73.7 \%$ & 0.895 \\
$>\mathbf{4 . 3 ~ n g / m L}$ & $(47.2-82.7)$ & $(82.2-99.9)$ & $(76.2-99.9)$ & $(56.9-86.6)$ & $(0.787-0.960)$ \\
\hline AFP & $90 \%$ & $75.9 \%$ & $79.4 \%$ & $88 \%$ & 0.895 \\
$>\mathbf{1 0 1} \mathbf{~ n g / m L}$ & $(73.5-97.9)$ & $(56.5-89.7)$ & $(62.1-91.3)$ & $968.8-97.5)$ & $(0.788-0.960)$ \\
\hline DKK1+AFP & $93.3 \%$ & $75.9 \%$ & $80 \%$ & $91.7 \%$ & 0.901 \\
$>\mathbf{1 0 2 . 2 n g / m L}$ & $(77.9-99.2)$ & $(56.5-89.7)$ & $(63.1-91.6)$ & $(73-99)$ & $(0.795-0.964)$ \\
\hline
\end{tabular}

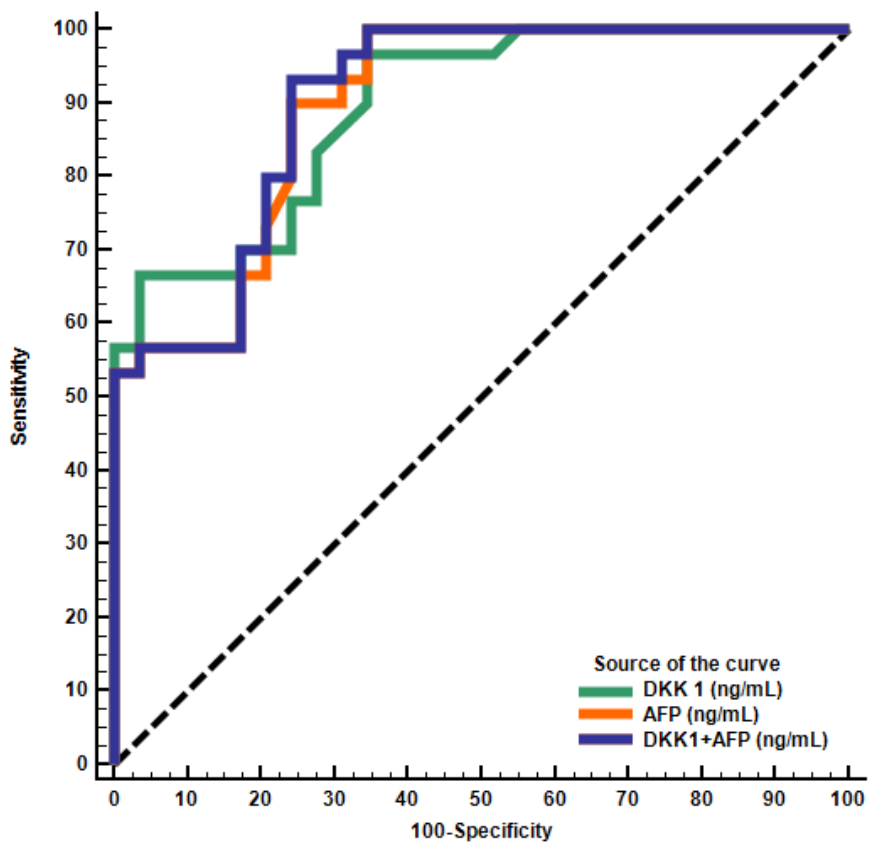

Fig. (3): ROC curve of DKK1, AFP and DKK1+AFP as diagnostic markers for HCC vs. cirrhotic patients without HCC 
Table (4): Laboratory findings before and after treatment in Group B

\begin{tabular}{|l|c|c|c|}
\hline \multicolumn{1}{|c|}{ Laboratory findings } & Before treatment $(\mathbf{N}=\mathbf{3 0})$ & After treatment $(\mathbf{N}=\mathbf{3 0})$ & P value \\
\hline AST $(\mathbf{U} / \mathbf{L})$ & $70.46 \pm 31.65$ & $55.26 \pm 25.12$ & $0.003(\mathrm{~S})$ \\
\hline ALT $(\mathbf{U} / \mathbf{L})$ & $60.60 \pm 24.98$ & $55.86 \pm 26.17$ & $0.004(\mathrm{~S})$ \\
\hline Bilirubin $(\mathbf{m g} / \mathbf{d l})$ & $1.93 \pm 0.77$ & $2.05 \pm 0.74$ & $0.131(\mathrm{NS})$ \\
\hline Albumin $(\mathbf{g} / \mathbf{d l})$ & $3.29 \pm 0.54$ & $3.08 \pm 0.45$ & $0.129(\mathrm{NS})$ \\
\hline PT $(\mathbf{s e c})$ & $15.83 \pm 2.98$ & $17.20 \pm 3.99$ & $0.057(\mathrm{NS})$ \\
\hline Creatinine $(\mathbf{m g} / \mathbf{d l})$ & $1.02 \pm 0.27$ & $1.07 \pm 0.24$ & $0.07(\mathrm{NS})$ \\
\hline Hemoglobin $(\mathbf{g} / \mathbf{d l})$ & $11.83 \pm 1.55$ & $11.23 \pm 1.45$ & $0.16(\mathrm{NS})$ \\
\hline Plt $\left(\mathbf{x 1 0} / \mathbf{m m}^{3}\right)$ & $110.76 \pm 38.61$ & $109.5 \pm 36.62$ & $0.231(\mathrm{NS})$ \\
\hline WBCs$\left(\mathbf{x 1 0} \mathbf{m m m}^{\mathbf{3}}\right)$ & $5.81 \pm 2.17$ & $5.10 \pm 1.99$ & $0.18(\mathrm{NS})$ \\
\hline AFP $(\mathbf{n g} / \mathbf{d l})$ & $361.93 \pm 289.91$ & $286.93 \pm 241.30$ & $<0.001(\mathrm{HS})$ \\
\hline DKK $\mathbf{( n g / d l )}$ & $4.97 \pm 2.23$ & $2.75 \pm 1.52$ & $<0.001(\mathrm{HS})$ \\
\hline
\end{tabular}

Table (5): Tumor markers 1 month after treatment among partial and complete responder's patients

\begin{tabular}{|c|c|c|c|}
\hline Tumor markers & Partial responder $(\mathbf{N}=9)$ & Complete responder $(\mathbf{N}=\mathbf{2 1})$ & P value \\
\hline AFP before & $402.11 \pm 264.37$ & $344.71 \pm 304.75$ & $0.402(\mathrm{NS})$ \\
\hline AFP after & $253.22 \pm 135.39$ & $301.38 \pm 276.34$ & $0.751(\mathrm{NS})$ \\
\hline DKK 1 before & $7.52 \pm 1.44$ & $3.88 \pm 1.49$ & $<0.001(\mathrm{HS})$ \\
\hline DKK 1 after & $3.36 \pm 1.57$ & $2.49 \pm 1.45$ & $0.167(\mathrm{NS})$ \\
\hline
\end{tabular}

Table (6): Validity of DKK1 (before treatment) in prediction of complete response to treatment; ROC curve Analysis

\begin{tabular}{|l|c|c|c|c|c|}
\hline Cut-off value & $\begin{array}{c}\text { Sens. \% } \\
(\mathbf{9 5 \%} \text { CI })\end{array}$ & $\begin{array}{c}\text { Spec. \% } \\
(\mathbf{9 5 \%} \text { CI })\end{array}$ & $\begin{array}{c}\text { PPV \% } \\
(\mathbf{9 5 \%} \text { CI })\end{array}$ & $\begin{array}{c}\text { NPV \% } \\
\mathbf{( 9 5 \% ~ C I ) ~}\end{array}$ & $\begin{array}{c}\text { AUC } \\
(\mathbf{9 5 \%} \text { CI) }\end{array}$ \\
\hline $\begin{array}{l}\text { DKK1 before } \\
\leq \mathbf{5 . 6 7} \mathbf{~ n g / m L}\end{array}$ & $100 \%$ & $100 \%$ & $100 \%$ & $100 \%$ & $100 \%$ \\
$(83.9-100)$ & $(66.4-100)$ & $(83.9-100)$ & $(66.4-100)$ & $(78.7-100)$ \\
\hline
\end{tabular}

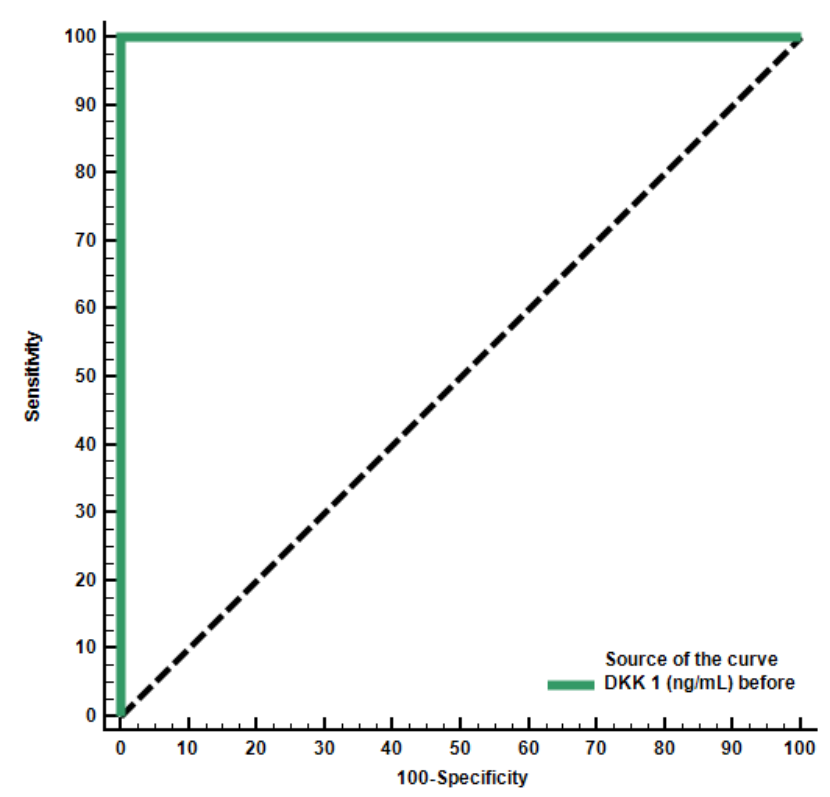

Fig. (4): ROC curve of DKK1 (before treatment) in prediction of complete response to treatment 


\section{DISCUSSION}

HCC is usually asymptomatic in early stages and tends to be invasive. Most HCC patients are presented with non-operable disease and this makes its early diagnosis critical for a good prognosis. Early HCC detection gives the opportunity to employ curative treatments such as liver transplantation, resection or local ablative therapy, which are the best way to prolong survival [17]. So, continuous researches are ongoing worldwide to find and evaluate an early sensitive and specific marker for HCC diagnosis [18].

Protein markers that measured in serum are the most applicable tests for clinical assessments and population studies $[\mathbf{1 9 , 2 0 ]}$. DKK1 is a secretory protein, specifically over expressed in cancer cells and is hardly detectable in human adult normal tissues except in placenta and embryonic tissues. Therefore, this protein might have potential as a cancer-specific serum biomarker for various human cancers including HCC [21].

In the present study, there was a statistically significant difference between the mean value of DKK1 in patients with HCC compared to patients with liver cirrhosis with mean values of $4.97 \pm 2.23 \mathrm{ng} / \mathrm{ml}$ and $2.28 \pm 0.90 \mathrm{ng} / \mathrm{mL}$ respectively. These results were in agreement with those of Shen et al., 2012 and Zhang et al., 2014 who showed that serum DKK1 level was higher in patients with HCC than cirrhotic patients, chronic hepatitis B and healthy control $[\mathbf{2 2 , 2 3 ]}$.

In our study, serum DKK1 level was more elevated in Child B cirrhotic patients than Child A patients (in group A) with mean level $9.95 \pm$ 1.04 and $1.87 \pm 0.49$ respectively. So, DKK1 levels increase with hepatic dysfunction. Also, serum DKK1 was more elevated in HCC patients with focal lesions $>3 \mathrm{~cm}$ than focal lesions $<3 \mathrm{~cm}$ (6.09 \pm 1.77 and $2.75 \pm 1.09$ respectively) in group B. This indicated that DKK1 level increase with disease progression from cirrhosis to small focal lesion then large focal mass. These results agreed with those of Tung et al., (2011) who reported a stepwise increase in serum DKK1 from cirrhosis group to early HCC then to advanced HCC group [24].

In this study, ROC curves revealed that the optimum diagnostic cut off value of DKK1 is 4.3 $\mathrm{ng} / \mathrm{mL}$ for diagnosis of HCC (AUC 0.895, 95\% CI $0.787-0.960$, sensitivity $66.7 \%$, specificity $96.6 \%$ ). This result is in agreement with that of Shen et al., (2012) and Zhang et al., (2014) who reported AUC (0.848 \& 0.84), sensitivity (69.1\% $\& 65 \%)$, specificity $(90.6 \% \& 94 \%)$ for $\mathrm{HCC}$ diagnosis versus cirrhosis control [22,23]. In contrast, Yang et al., (2013) showed that the DKK1 AUC (0.717) for HCC diagnosis was lower than the AUC in our study (0.895) [26].

In the present study, diagnostic cut off value for AFP was > $101 \mathrm{ng} / \mathrm{mL}$ for $\mathrm{HCC}$ in cirrhotic patients with $90 \%$ sensitivity, $75.9 \%$ specificity and 0.895 AUC. Serum DKK1 had similar AUC as AFP, higher specificity and lower sensitivity than AFP and this could be due to small sample size and only cirrhotic patients included as a control group not healthy control. This was in agreement with Nakamura et al., 2006 who showed that the cut off value of AFP for HCC diagnosis was $100 \mathrm{ng} / \mathrm{ml}$ with (33\%) sensitivity and $(99 \%)$ specificity [27]. In contrast, Farinati et al., 2006; and Debruyne and Delanghe, 2008 reported other sensitivity, specificity and cut off value for AFP for HCC diagnosis [28,29].

A greater proportion of HCC patients in our study were positive for DKK1 than for AFP. Furthermore, 8 of 13 AFP negative HCC patients had positive DKK1 result and all AFP-positive patients had + ve DKK1 results (Fig. 1; Fig. 2). The ROC curves for DKK1 indicated the diagnosis of HCC irrespective of AFP status. This finding was in agreement with that of Shen et al., (2012) and Yang et al., (2013) [22,26].

In this study, testing of both DKK1 and AFP increased the diagnostic accuracy for $\mathrm{HCC}$ compared with either test alone (AUC 0.901, 95\% CI, 0.795-0.964, sensitivity 93.3\%, and specificity 75.9). This was in agreement with $\mathrm{Ge}$ et al., 2015 who showed that testing of both AFP and DKK1 had AUC 0.93, sensitivity $88.8 \%$, and specificity $88.12 \%$ [30]. In contrast, Eun et al., 2016 reported that testing of AFP and DKK1 had AUC 0.76 , sensitivity $78 \%$, and specificity $73 \%$ [31].

Group B patients underwent either radiofrequency ablation (12 patients) or ethanol injection (18 patients) according to the Barcelona Clinic Liver Cancer (BCLC) staging system [32]. Percutaneous ablation is the preferred treatment option for patients in this study. Both radiofrequency ablation and percutaneous injection therapy have a welldocumented loco-regional antitumor effect and are the most two commonly employed methods for HCC treatment $[\mathbf{3 3}, 34]$. Liver transplantation and surgical resection are the standard treatment modality to achieve a long-term survival. 
However, both of them are major surgery with many complications and have negative impact on patients' especially cirrhotic $[35,36]$.

This study showed no statistically significant difference between patients treated with either radiofrequency ablation or ethanol injection as regards AFP and DKK1. There was decrease in mean level of both markers after treatment, with mean level of DKK1 $4.97 \pm 2.23 \mathrm{ng} / \mathrm{ml}$ pretreatment and $2.75 \pm 1.52 \mathrm{ng} / \mathrm{ml}$ post-treatment. These findings agreed with those of Tung et al. [24] and Shen et al. [22] who reported that serum DKK1 levels dropped in HCC patients following surgery. Also, Yamabuki et al., (2007) reported reduced DKK1 serum levels following surgical resection of primary tumors in esophageal squamous cell carcinoma and lung cancer patients [37].

After 1 and 3 months of treatment, there was no statistically significant difference between both groups regarding procedure success, stationary ablation, recurrence, decompensation and survival. Both techniques were successful $(83.3 \%$ with radiofrequency and $61.1 \%$ with ethanol injection).

We found that level of DKK1 was significantly decreased after treatment. DKK1 before treatment was $7.52 \pm 1.44$ in patients with partial response and 3.88 \pm 1.49 in patients with complete response and this suggest that DKK1 may have a prognostic role in predicting treatment response. DKK1 was assessed only one month after treatment where no recurrence is detected during this period with CT. Therefore, we couldn't emphasize that level of DKK1 elevated again with tumor recurrence.

No studies have been done before to put a cut off value for DKK1 for prediction of treatment response even after surgical resection. In this study, we have a cut off value for DKK1 for prediction of complete response to treatment. This value was $\leq 5.67 \mathrm{ng} / \mathrm{mL}$ (AUC $100 \%, 95 \%$ CI $78.7-100$, sensitivity $100 \%$ and specificity $100 \%$ ) and this value need more studies to be confirmed and to prove prognostic role of DKK1 in prediction of treatment response, recurrence and survival.

From this study and its results, serum DKK1 is a secretory protein, it can be easily detected in circulation and it is elevated in HCC cells and not in normal cells. Serum DKK1 could be used to diagnose HCC, especially with inconclusive AFP. Furthermore, serum DKK1 can complement
AFP levels to improve the diagnostic accuracy of HCC. DKK1 could predict treatment response and may be a promising prognostic marker for HCC.

Funding: None.

Conflicts of interest: None.

Ethical approval: The protocol of the study was approved by the ethical committee of Faculty of Medicine, Zagazig University. Informed consents were obtained from all patients.

\section{REFERENCES}

1. Altekruse SF, McGlynn KA, Reichman ME. Hepatocellular carcinoma incidence, mortality, and survival trends in the United States from 1975 to 2005. J Clin Oncol. 2009; 27: 1485-1491.

2. Mokhtar N, Gouda I, Adel I. Cancer Pathology registry (2003-2004) and time trend analysis. Department of pathology, NCI. 2007.

3. Omar A, Abou-Alfa GK, Khairy A, Omar H. Risk factors for developing hepato-cellular carcinoma in Egypt. Chin Clin Oncol. 2013; 2 (4): 43.

4. Severi T, van Malenstein H, Verslype C, van Pelt JF. Tumor initiation and progression in hepatocellular carcinoma: risk factors, classification, and therapeutic targets. Acta Pharmacol Sin. 2010; 31:1409-1420.

5. Habib M, Mohamed MK, Abdel Aziz F, Magder LS, Abdel-Hamid M, Gamil F, et al. Hepatitis C Virus in a community in the Nile Delta: risk factors for Seropositivity. Hepatology 2001; 33 (1): 2485 .

6. Nguyen VT, Law MG, Dore GJ. Hepatitis Brelated hepatocellular carcinoma: epidemiological characteristics and disease burden. J Viral Hepat. 2009; 16:453-463.

7. Kanwal F, Hoang T, Kramer JR, Asch SM, Goetz $\mathrm{MB}$, Zeringue $\mathrm{A}$, et al. Increasing prevalence of HCC and cirrhosis in patients with chronic hepatitis C virus infection. Gastroenterology 2011; 140:1182-1188.e1.

8. Yao DF, Dong ZZ, Yao M. Specific molecular markers in hepatocellular carcinoma. Hepatobiliary Pancreat Dis Int. 2007; 6: 241247.

9. Daniele B, Bencivenga A, Megna AS, Tinessa V. $\alpha$ fetoprotein and ultrasonography screening for hepatocellular carcinoma. Gastroenterol. 2004; 127: S108-12.

10. Sheu JC, Sung JL, Chen DS, Lai MY, Wang TH, $\mathrm{Yu}$ JY, et al. Early detection of hepatocellular carcinoma by real-time ultrasonography. A prospective study. Cancer 1985; 56, 660-666.

11. Nguyen MH, Garcia RT, Simpson PW, Wright TL, Keeffe EB. Racial differences in effectiveness of alpha-fetoprotein for diagnosis of 
hepatocellular carcinoma in hepatitis $\mathrm{C}$ virus cirrhosis. Hepatology 2002; 36, 410-417.

12. Fatima S, Lee NP, Luk JM. Dickkopfs and Wnt/ $\beta$-catenin signalling in liver cancer. World $J$ Clin Oncol. 2011; 2:311-25.

13. MacDonald BT, Tamai K, He X. Wnt/ $\beta$-catenin signaling: components, mechanisms, and diseases. Dev Cell. 2009; 17: 9-26.

14. Fedi P, Bafico A, Soria AN, Burgess WH, Miki $\mathrm{T}$, Bottaro DP, et al. Isolation and biochemical characterization of the human Dkk-1 homologue, a novel inhibitor of mammalian Wnt signaling. J Biol Chem. 1999; 274: 19465-72.

15. Hall CL, Daignault SD, Shah RB, Pienta kJ, Keller ET. Dickkopf-1 expression increases early in prostate cancer development and decreases during progression from primary tumor to metastasis. Prostate 2008; 68: 1396-404.

16. Shiina $S$, Tagawa $\mathrm{K}$, Unuma $\mathrm{T}$, Fujino H, Uta Y, Niwa Y, et al. Percutaneous ethanol injection therapy of HCC: analysis of 77 patients. AJR 1990; 155: 1221.

17. Forner A, Llovet JM, Bruix J. Hepatocellular carcinoma. Lancet 2004; 379:1245-55.

18. Filmus J, Capurro M. Glypican 3 and alphafetoprotein as diagnostic tests for hepatocellular carcinoma as diagnostic tests. Mol. Diagn. 2004; 8: 207.

19. Brawley O, Ankerst D, Thompson I. Screening for prostate cancer. CA Cancer J Clin 2009; 59: 264-73.

20. Malaguarnera M, Vacante M, Fichera R, Cappellani A, Cristaldi E, Motta M, et al. Chromogranin A (CgA) serum level as a marker of progression in hepatocellular carcinoma (HCC) of elderly patients. Arch Gerontol Geriatr 2010; 51:81-5.

21. Le Sheng S, Huang G, Yu B, Qin WX. Clinical significance and prognostic value of serum Dickkopf-1 concentrations in patients with lung cancer. Clin Chem. 2009; 55:1656 - 64.

22. Shen Q, Fan J, Yang XR, Tan Y, Zhao W, Xu Y, et al. Serum DKK1 as a protein biomarker for the diagnosis of hepatocellular carcinoma: a largescale, multicentre study. Lancet Oncol. 2012; 13(8): 817 - 826.

23. Zhang J, Zhao Y, Yang Q. Sensitivity and specificity of Dickkopf-1 protein in serum for diagnosing hepatocellular carcinoma: a metaanalysis. Int J Biol Markers 2014; 29(4):e403 e410.

24. Tung EK, Mak CK, Fatima S, Lo RC, Zhao H, Zhang $\mathrm{C}$, et al. Clinicopathological and prognostic significance of serum and tissue Dickkopf-1 levels in human hepatocellular carcinoma. Liver Int. 2011; 31: 1494-1504.

25. Kim SU, Park JH, Kim HS, Lee JM, Lee HG, Kim $\mathrm{H}$, et al. Serum Dickkopf-1 as a Biomarker for the Diagnosis of Hepatocellular Carcinoma. Yonsei Med J. 2015; 56(5):1296-1306.
26. Yang H, Chen GD, Fang F, Liu Z, Lau SH, Zhang JF, et al. Dickkopf-1: as a diagnostic and prognostic serum marker for early hepatocellular carcinoma. Int. J Biol. Markers 2013; 28(3): 286297.

27. Nakamura S, Nouso K, Sakaguchi K, Ito YM, Ohashi Y, Kobayashi Y, et al. Sensitivity and specificity of des-gamma-carboxy prothrombin for diagnosis of patients with hepatocellular carcinomas varies according to tumor size. The American journal of gastroenterology 2006; 101(9), pp.2038-2043.

28. Farinati F, Marino D, De Giorgio M, Baldan A, Cantarini M, Cursaro C, et al. Diagnostic and prognostic role of alpha-fetoprotein in hepatocellular carcinoma: both or neither? Am J Gastroenterol. 2006; 101: 524-32.

29. Debruyne EN, Delanghe JR. Diagnosing and monitoring hepatocellular carcinoma with alphafetoprotein: new aspects and applications. Clin Chim Acta. 2008; 395:19-26.

30. Ge T, Shen Q, Wang N, Zhang Y, Ge Z, Chu W, et al. Diagnostic values of alpha fetoprotein, dickkopf - 1, and osteopontin for hepatocellular carcinoma. Med Oncol. 2015; 32(3):59.

31. Jang ES, Jeong SH, Kim JW, Choi YS, Leissner P, Brechot C. Diagnostic Performance of AlphaFetoprotein, Protein Induced by Vitamin K Absence, Osteopontin, Dickkopf-1 and Its Combinations for Hepatocellular Carcinoma. PloS one. 2016; 11(3):e0151069.

32. Forner A, Reig ME, de Lope CR, Bruix J. Current strategy for staging and treatment: the BCLC update and future prospects. Semin Liver Dis. 2010; 30:61-74.

33. Livraghi T, Goldberg SN, Lazzaroni S, Meloni F, Solbiati L, Gazelle GS, et al. Small hepatocellular carcinoma: treatment with radio-frequency ablation versus ethanol injection. Radiology 1999; 210: 655-61.

34. Huo TI, Huang YH, Wu JC, Lee PC, Chang FY, Lee SD. Survival benefit of cirrhotic patients with hepatocellular carcinoma treated by percutaneous ethanol injection as a salvage therapy. Scand $J$ Gastroenterol. 2002; 37(3): 350-5.

35. Izumi R, Shimizu K, Ii TO, Yagi M, Matsui O, Nonomura A, et al. Prognostic factors of hepatocellular carcinoma in patients undergoing hepatic resection. Gastroenterology 1994; 106(3): 720-7.

36. Bruix J, Sherman M. Management of Hepatocellular Carcinoma. Hepatology 2005; 42(5): 1208-36.

37. Yamabuki T, Takano A, Hayama S, Ishikawa N, Kato T, Miyamoto M, et al. Dikkopf-1 as a novel serologic and prognostic biomarker for lung and esophageal carcinomas. Cancer Res. 2007; 67: 2517-25. 
Peer reviewer: Maysaa Abdalla, Professor of Tropical Medicine, Faculty of Medicine, Zagazig University, Egypt.
Editor: Tarik Zaher, Professor of Tropical Medicine, Faculty of Medicine, Zagazig University, Egypt 